\title{
The challenge of implementing a patient-centric EMR
}

Cite as: CMAJ 2019 February 4;191:E144-5. doi: 10.1503/cmaj.109-5706

Posted on cmajnews.com on Jan. 16, 2019.

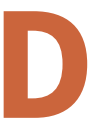

r. David Chan expressed amusement that high-tech giant Apple is courting the United States Department of Veterans Affairs with a system that would allow patients to store electronic medical records (EMRs) on their mobile devices. A professor emeritus of family medicine at McMaster University, Chan spent much of his career strug-
Chan pointed out, however, that Apple is focusing on something that has been missing from other approaches - the end user. "When we talk about the interoperability of medical records, the only one you really want to interact with should be the patient," he said. "Apple is suggesting that relevant information should be stored in the patient's device."

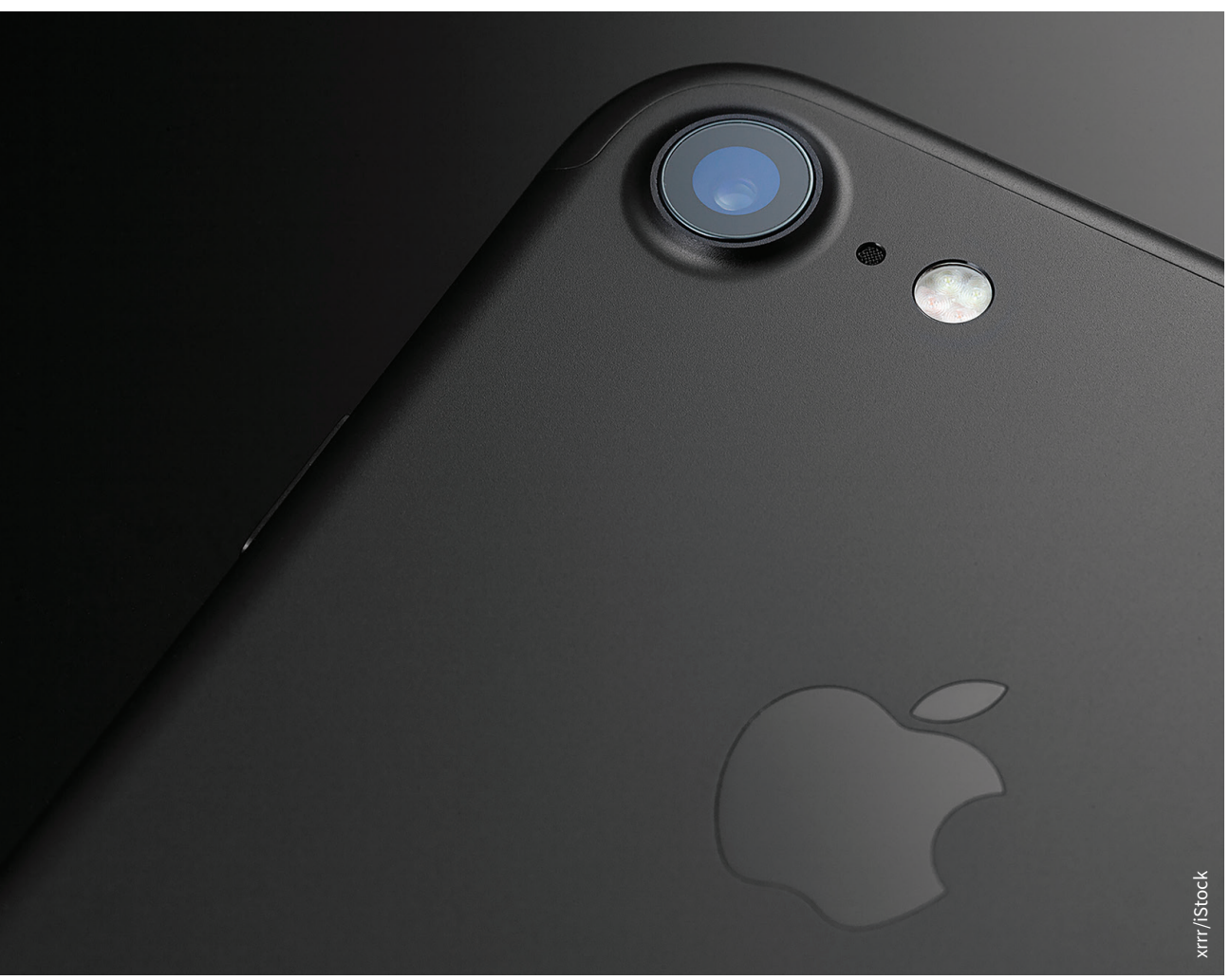

High-tech giant Apple wants to bring the EMR to the iPhone.

gling with the logistics of EMRs and regards this move as yet another corporate intrusion into a medical information technology landscape littered with proprietary software systems that don't communicate with each other.
Many tech companies store critical information - passwords, fingerprints, facial recognition data - in databases that are inaccessible to customers, but Apple secures that information by restricting it to individual devices.
According to Chan, commercial EMRs have generally stored medical information in proprietary networks that don't allow patients to manage their own files. "Consumers are just out of luck," he said. "There's simply no way you can access these gigantic databases."

A patient-centric platform on a mobile device with appropriate sensors, however, could provide not only easier access to medical information, but also real-time monitoring of health indicators such as heartbeat or blood sugar. "If you obtain people's consent and you follow them forward with proper communication, you discover knowledge that is far more valuable," said Chan.

That goal is welcomed by Dr. Ewan Affleck, who nevertheless anticipates that business interests will continue to undermine the goals of health care delivery. "The patient-centric ownership and custodianship of the information is all lovely," he said. "But the corporatization makes me nervous."

Affleck's career in the Northwest Territories' health care system has been dominated by efforts to weave an unruly collection of professional and bureaucratic threads into what has emerged as an example of a fully integrated system for tracking patient information.

"This was not a technology project; it was an anthropology or a sociology project," he said.

It took 17 years of negotiating with people in the health system's many different departments to get all to adopt the same EMR. There was resistance from many providers and administrators about the idea of a shared, patient-centric information system, but Affleck continued to make the case and the result is a solution 
that allows for seamless and secure sharing of data and, ultimately, more efficient service to patients.

"The lack of interoperability is perhaps the single most important driver of the disarray that has occurred with the digital revolution in health care," he said.

Some EMRs are managed by private companies, some by government agencies, and others are open-source. Unfortunately, the effort required to make them compatible increases with each one that enters the market. What results is disorganized health information that can compromise patient care and frustrate health service staff.

Affleck uses the word "chaos" to describe the impact that poor technology architecture and data overload can have on physicians and other health workers.
The root of the problem is that the digitization of health information was not designed to uphold a foundational principle of a coherent medical record: it should follow patients throughout their lives. The management of these records was ceded to a jumble of public and private interests, which subsequently stored them in disparate and sometimes inaccessible formats.

"It happened quite passively, without people recognizing the implications," he said. "We fell in love with the shiny technology, without recognizing it needs to [work] across the continuum of care to function safely. We forgot that the value proposition of the digital revolution is information, not technology"

Providing patients with access to their EMRs might address some of these short- comings, but that will prove challenging. "In the health industry, there has been widespread resistance on the part of governments, physicians and other stakeholders to hand over access to patient information to patients," said Affleck.

Apple's strategy with veterans could represent an attempt to counter this resistance by enlisting a new generation of patients who have grown up in an environment dominated by electronic access to information, the so-called "digital natives." This generation includes tech-savvy doctors who are tired of inadequate health information technology that runs counter to principles of providing quality care.

"Digital natives are saying "this is crap'," said Affleck, "and they're right."

Tim Lougheed, Bath, Ont. 